\title{
Del mercado al instinto (o de los intereses a las pasiones)
}

\author{
FÉLIX OVEJERO
}

Universidad de Barcelona

\begin{abstract}
«Nos mantienen con vida exiraños equilibrios que no son conprensibles desde la propia vida,

Carlos Marzal
\end{abstract}

\author{
"Cuando todo sucede naturalmente las \\ cosas son todavia más extrañas.s
}

R. M. Rilke
La organización de la vida social se ha enfrentado al problema de armonizar los objetivos de los individuos y los objetivos colectivos. Con sus importantes matices, ese problema está en la raíz de importantes discusiones de las teorias sociales y normativas contemporáneas: la configuración de una voluntad general a partir de voluntades individuales, la posibilidad de la acción colectiva, la aparición y la necesidad de la confianza, la búsqueda de escenarios de diálogo entre individuos comprometidos con criterios de racionalidad y de interés general, la obtención de reglas de justicia aceptables para personas con concepciones morales dispares, la participación comprometida de los ciudadanos en la vida cívica. En la trastienda de esas discusiones aparece un problema de disposición societaria (DS en lo sucesivo): hay la suficiente interacción como para que los problemas aparezcan pero no la suficiente como para que se disuelvan ${ }^{1}$. Si los individuos no comparten algunos principios, criterios, intereses o predisposiciones, la vida compartida resulta imposible y con ella cualquier discusión acerca de cómo vivir o qué decisión tomar. Ahora bien, si todos caminan como un solo hombre bajo un ideal común hasta el mínimo detalle, si ni siquiera se concibe la posibilidad de la discrepancia o de la elección, desaparece la misma idea de moralidad o de vida cívica. El territorio cívico parece situarse entre la moral de los lobos y la moral del hormiguero. La DS apunta a la necesidad de asegurar la sociabilidad sin imposibilitar la discrepancia.

En el diagnóstico de que la DS es un problema normativo han coincidido comunitaristas y liberales, las tradiciones más importantes de la fifosofía política contemporánea, aun cuando unos estén más cerca de las hormigas y otros se reconozcan, con resistencia o resignación, en cierta idea de libertad presocial, anterior a la ley, en la que suena un eco amortiguado de la vieja máxima (Homo homini lupus) de Plauto popularizada por Hobbes ${ }^{2}$. Los primeros han querido moralizarlo hasta el empacho. La resolución de la DS requiere una genuina comunión moral, todo lo demás es el principio de la disgregación. Los liberales, por su parte, han tratado de omitir toda presunción normativa y obtener una suerte de motor inmóvil de la moral social. Para ello han construido artificiosos contratos sociales inaugurales en los que unos individuos presociales ( $\mathrm{y}$ premorales) buscan un acuerdo sobre unas reglas de juego laicas, no comprometidas normativamente, capaces, sin embargo, de asegurar el escenario de la moral pública. Se verá que ninguna de esas propuestas ha conseguido abordar el verdadero problema: encontrar un fundamento a la comunidad normativa, que haga posible la vida cívica, pero que no sea él mismo normativo. Entre otras razones porque, antes que un fundamento, lo que hay que encontrar es un mecanismo que asegure la reproducción sin invocar instancias normativas, un juego (social) tal 
que las propias condiciones del juego garanticen la reproducción del juego y de los jugadores.

El mercado ha constituido la herramienta analítica más poderosa en el intento de solventar la DS. La mano invisible ha sido propuesta como ese mecanismo, como ese terreno capaz de asegurar el funcionamiento de la vida social, más allá de todo cimiento normativo. Las diferencias éticas empezarian, en todo caso, después ${ }^{3}$. Esa iniciativa ha llegado a sus últimas consecuencias de la mano de aquellas teorías que han querido disolver el territorio moral en el intercambio y la negociación. Con independencia de su circunstancial -aunque frecuente- matrimonio con el mercado, tales propuestas apuntaban en la dirección correcta al destacar que en la DS hay más aspectos que los morales y que cargar la tinta sobre ellos puede contribuir a oscurecer los problemas. Su error consistía en pensar que detectar el caracter «amoral» del escenario cívico equivale a declarar amoral (el argumento de) la obra civica y, sobre todo, en creer que el cimiento premoral del escenario tenía que ser cl homo aconomicus, los agentes egoístas presociales que convierten su vida común en un cálculo.

En las páginas que siguen se verá, en primer lugar, la centralidad de la DS en la discusión contemporánea, se verá cómo el mercado, que en principio aparece como un buen candidato para solucionar el problema de la DS, se revela, a la postre, como un mecanismo perverso. A continuación se tratará de mostrar cómo las propuestas deliberativas se revelan insuficjentes para asegurar, por si mismas, el territorio civico, $o$ dicho de otra manera, en positivo: para edificar un escenario deliberativo se requieren unas condiciones de cohesión y motivación, una ontología social ${ }^{4}$ que no sea ella misma producto del escenario deliberativo. La parte final sugiere una fundamentación naturalista que, en rigor, equivale a disolver el problema de la DS, a mostrar, por pasiva, que se trata, en buena medida, de uno de esos seudoproblemas tan frecuentes en la historia del pensamiento filosófico, heredado esta vez de ese imposible hombre presocial que está en la base del liberalismo contemporáneo ${ }^{5}$.

\section{La disposición de sociabilidad}

La DS está en el centro de la mejor teoría normativa contemporánea. La evolución de Rawls se puede entender como un permanente intento de solucionar ese problema. El camino que lleva desde la Teoría de la justicia hasta el Liberalismo político viene marcado por la preocupación por la estabilidad que hace posible el escenario público: los ciudadanos se deben sentir motivados para defender los principios que inspiran su sociedad de tal modo que cuando se producen desviaciones, el equilibrio se restablezca automáticamente, sin quebrar el escenario ${ }^{6}$. Ahora bien, esa motivación cívica no tjene que depender de una idea de bien, si se quiere compatible con el respeto al whecho del pluralismo», con la irreductible diversidad de ideas acerca de cómo vivir. Esa es la raíz de la evolución de Rawls, pero también la raíz de sus problemas ${ }^{7}$. Una idea de justicia que no se amarra en lo que a los distintos ciudadanos les parece bien (o mal) carece de fuerza vinculante, es incapaz de comprometer a aquellos sobre los que se quiere asentar. En breve, Rawls anda a la búsqueda de un cemento social distinto de la «simple coordinación» y normativamente agnóstico que asegure una base a la vida ć́vica. $\mathrm{La}$ perspectiva comunitaria tiene bastante de resolución retórica. Si los problemas aparecen porque hay intereses en conflicto, empecemos por suponer que no los hay. La DS parece disiparse si todos los ciudadanos participan de una común idea de bien, si tienen los mismos criterios de valoración, metas comunes que encarar y un código compartido para resolver conflictos 
y ordenar preferencias. Apenas resulta necesario destacar la irrealidad de suponer quc los ciudadanos tienen una idea de bien compartida, no menor que la de presumir que, aun si tal fuera el caso, esa idea de bien es capaz de proporcionar criterios de decisión inequívocos ${ }^{8}$. La comunidad de los santos que resuelve la DS no es más plausible que dos de los personajes más maltratados, por su irrealidad, por la critica filocomunitaria del liberalismo: el homo aconomicus omnisciente y calculador que ascgura la eficiente asignación en el mercado y el suje to trascendental y descarnado que se siente comprometido por hipotéticos o contrafácticos contratos sociales.

Sin embargo, la propuesta comunitaria, en su irrealismo, por omisión, ayuda a detectar algunas dimensiones de la DS normalmente descuidadas por la filosofía política. Pues tampoco es verdad que la estabilidad quede asegurada con la benevolencia o la comunión de ideales. Sin duda, una comunidad de monjes cstá en buena disposición para resolver muchos problemas de acción colectiva. Las tareas comunes se llevarian a cabo sin noccsidad do penalizar a unos inexistentes free riders. Pero no todos los problemas desaparecen. Si se produce un incendio en la bolsa de valores, cuando cada uno intenta salvarse sin atender a los demás, con su acción alimenta la catástrofe de la que todos acaban como víctimas. Pero no irían mejor las cosas en un convento en el que cada uno de los monjes decidiera ceder el paso a los demás y ser el último en salir. Con un poco más de realismo las cosas resultan todavía más complicadas. Una sociedad elementalmente comunitarista, en la que no cxista una homogeneidad cultural absoluta, es una sociedad abocada al conflicto y la segregación, más allá de la voluntad (multicultural) de los ciudadanos. En uno de sus sugestivos modelos Schelling mostró cómo una sociedad en donde los individuos tienen preferencias del tipo «no me importa tener vecinos de otro grupo cultural siempre que no constituyan una mayoría» desemboca en procesos inestables frente a menores perturbaciones aleatorias (un cambio de residencia de un individuo) cuyo resultado final es una alta segregación". Aun con «comunitaristas liberales» contrarios a la segregación, dispuestos a aceptar otros modos de vida, se produce un efecto perverso, contrario a la voluntad de cada uno, que hace imposible la estabilidad de los principios sobre los que se asentaba la sociedad.

En resumen, hay problemas de coordinación (de armonía de objetivos) y de estabilidad que no tienen que ver simplemente con la contraposición de las concepciones del mundo. La existencia de conflictos e inestabilidades ajenos a diferencias normativas no escapa, por el contrario, a aquellas teorias que hacen de la justicia, y en general de las normas morales, un simple capítulo de las teorías de la negociación 0 , más exactamente, de la teoría de la elección racional ${ }^{10}$. Con todas sus dificultades ${ }^{11}$, estas teorías destacan con pertinencia la existencia de continuidades cntre los problcmas de coordinación y los problemas normativos. Desde su perspectiva, no habria una diferencia esencial entre las normas de etiqueta y la justicia, entre la convención de conducir por la derecha y la condena moral de la mentira ${ }^{12}$. Resultarian insostenibles sociedades en donde cada uno conduce por donde quiere o donde reina una desconfianza generalizada. En todos esos casos, lo que al final hay es un sistema de resolución convencional de intereses en conflicto que requieren una solución coordinada. Lo importante es que se producen situaciones de equilibrio en las que nadie tiene ninguna razón (interés) para modificar su conducta mientras los otros mantengan la suya (dadas unas preferencias y una situación inicial). De ese modo cada uno con su acción asegura la acción de los otros y, de paso y sin pretenderlo, un resultado que es consecuencia de la acción de todos. En 
tales escenarios (de non regret) los individuos no lamentan sus elecciones, después de constatar el resultado final ${ }^{13}$. Sean cuales sean sus motivaciones, siguiendo su mejor estrategia, todos se orientan en la misma dirección. La convergencia en el resultado es independiente de las motivaciones de cada uno.

Estas estrategias resultan, sin embargo, menos convincentes a la hora de explicar la reproducción de los equilibrios, su estabilidad, en particular en todos los casos distintos de la coordinación pura. El propio individuo que se acoge a la moral desde el cálculo y la conveniencia es un perpetuo free rider en estado latente dispuesto a aprovechar cualquier oportunidad de beneficio. Al cabo, está muy bien que los demás digan la verdad y precisamente por ello, porque reina la confianza, me puedo beneficiar de la mentira, siempre, claro es, que los demás no piensen lo mismo. Por otra parte, conviene advertir que esos escenarios y equilibrios no excluyen que el resultado, inflexible, sea el menos deseado por todos. En el incendio de la bolsa, nadie escapa a la catástrofe precisamente cuando cada uno hace lo mejor que puede hacer, dado lo que los otros hacen, y sale lo más rápido posible ${ }^{14}$. En suma, además de que el resultado sca, en algún sentido, independiente de las motivaciones de los individuos, se necesita que sea estable y óptimo socialmente.

De un modo más sistemático, el mecanismo capaz de asegurar el escenario social tiene que satisfacer:

1. La amonia de objetivos exige que apunten en la misma dirección las acciones de los individuos y los objetivos sociales. Es el requisito de «coordinación» destacado por las teorías de la negociación y de la convención: cada uno con su acción debe contribuir a un equilibrio que sea interesante para él y para todos. En principio, la armonia de objetivos no excluye la "comumión de los santos", no impide que el vínculo social tenga base normativa. De ahí el siguiente requisito.

2. El agnosticismo nomativo, el requisito «liberal» por excelencia y del que arranca la preocupación rawlsiana por la estabilidad: la cohesión y el compromiso no deben depender de una idea de bien. El problema con el agnosticismo liberal, como se apuntó, radica en que no asegura la sociabilidad. Aun si fuera posible que, en sociedades en las que «el hecho del pluralismo resulta irrevocable», los criterios de dilucidación no dependan de concepciones específicas del bien, con ello no se asegura el compromiso con las decisiones. Es cierto que existen vínculos circunstanciales entre la participación en el juego social y la imparcialidad de las reglas de juego: nadie aceptaría los resultados de reglas que favorecen a otros. Sin embargo, en tanto no se comprometen con nadie, también dejan indiferentes a todos, carecen de fuerza vinculante. En la medida que los criterios de decisión se quieren laicos quedan desprovistos de vigor para comprometer a los ciudadanos: las razones que valen para los individuos no son las que tienen en cuenta al juzgar una decisión. La «solución» liberal no funciona, pero sí persiste el objetivo: asegurar la vida cívica desde un asidero que no sea normativo $o$, para volver al viejo léxico, trascendental. $\mathrm{El}$ «problemas, que es más general que la fuerza vinculante, se puede solventar no sólo a través del compromiso con los criterios de valoración de los ciudadanos, sino también a través de un vínculo que sujete a los individuos al escenario social pero sin apelar a sus principios normativos.

3. El algoritmo social. Que «los objetivos de los individuos apunten en la misma dirección que los objetivos sociales» no quiere decir que sean necesariamente los mismos, sino que los resultados de las acciones de los individuos coinciden con los objetivos generales. En ese sentido, el requisito de la amonia requiere una matización: la armonía entre las acciones de 
los individuos y los objetivos comunes no tiene que depender estrechamente de las motivaciones de los individuos. Basta con que las acciones de los individuos aseguren el designio al cual sirven. Las comunidades científicas son un buen ejemplo de algoritmo social. Los científicos pueden estar interesados en la fortuna, la fama o el éxito sexual, pero, dadas las reglas de juego de la comunidad científica, para obtener sus objetivos han de perseguir la verdad. Por supuesto, entre ellos habrá muchos que únicamente estén interesados en la verdad, pero no son necesarios sin más. Con independencia de las metas de cada cual, el mecanismo social asegura el buen funcionamiento ${ }^{15}$. El resultado interesante no depende de los fines específicos de los individuos en los que se realiza o kinstancia» (aunque obviamente se requieren algunas condiciones que lo hagan posible, por ejemplo su calidad intencional). No resulta necesario ninguna armonia preestablecida desde una común idea de vida buena. En este sentido cabe abordarlo como un proceso que se comporta «como si» estuviera orientado por los objetivos compartidos, aunque en sí mismo sea resultado de un proceso ciego, mecánico.

4. La estabilidad reproductiva. Los requisitos anteriores no aseguran la perdurabilidad de los procesos. Un sistema de competición deportiva es un algoritmo que cumple los requisitos anteriores pero que se acaba una vez se ha determinado al ganador. No asegura la reproducción de la competición. Interesa que el proceso se reproduzca y que se reproduzca de un modo estable. Hay que asegurar que el mecanismo que mantiene al escenario social sea también capaz de hacer que se recupere de elementales perturbaciones sin que se modifique la armonía de objetivos. Recuperación que, si no quiere violarse el requisito de agnosticismo, ha de realizarse, además, sin la intervención de ninguna instancia ajena al propio mecanismo reproductor, instancia que necesi- taría una referencia normativa. El requisito de estabilidad no es de fácil cumplimiento para las teorias que reducen la moral a un escenario de negociación. No basta con mostrar que los individuos tienen abiertas opciones que aseguran la resolución de los conflictos o el mantenimiento, por ejemplo, de una senda de crecimiento ${ }^{16}$. Hay que mostrar que las propias condiciones del juego propician la reproducción del juego.

\section{El mercado como solución a la $D S$}

La teoría económica ha consumido buena parte de su historia en la búsqueda de algún mecanismo capaz de armonizar las acciones de cada uno con los objetivos de todos de tal manera que las primeras produzcan los segundos de un modo automático, sin pretenderlo, mediante un proceso capaz de autorreproducirse y sin dependencia de instancias normativas. Durante bastante tiempo el mercado ha aparecido como ese motor inmóvil de la ética social ${ }^{17}$. Con independencia de los propósitos específicos de los individuos, el juego competitivo obliga a comportarse de modo eficiente. Los recursos se asignan allí donde hay oportunidades desaprovechadas. La escasez en condiciones de expresarse como demanda se detecta a través de (la subida de) los precios, y las necesidades insatisfechas (y con dinero) se atienden. Sin que nadie se ocupe de ello, la coordinación de las tareas productivas se asegura a través del sistema de precios. Éstos, en su movimiento, señalan qué producir, cómo producirlo, en qué cantidades y para quién. No sólo eso. El mecanismo se reproduce alimentándose de las elecciones de los individuos y sin ocasión para el desvio de la trayectoria. El territorio de la moralidad queda disuelto en un escenario competitivo. Éste impone una única respuesta a las tres preguntas que sitúan el perímetro de la elección moral: ¿qué 
debo hacer?, ¿qué puedo hacer?, ¿qué quiero hacer? Io que debo hacer, lo que asegura el buen funcionamiento social, el bienestar, es aquello que quiero hacer, atender a mis intereses, y que es, además, lo único que puedo hacer, lo que la competencia me fuerza a hacer. En suma, lo deseable es lo deseado.

No es casual que la imagen que más ha acompañado al mercado haya sido la de «la mano invisible» ${ }^{18}$ : una máquina con designio pero sin ingeniero que asegura que los objetivos de todos se consiguen, que permiten «promover un fin que no cstaba en las intenciones de los individuos». Adam Smith, fascinado por la «adecuación de la máquina para alcanzar el fin para el cual fue diseñada", describirá la sociedad como uuna grandiosa máquina cuyos movimientos regulares producen efectos beneficiosos\%, «El hambre, la pasión entre los sexos, el amor al placer y el odio al sufrimiento, nos llevan a actuar (...) sin consideración de su tendencia hacia los beneficiosos fines que el Gran Director de la naturaleza intenta producir a través de ellos.n Su cultura científico-natural ${ }^{19} \mathrm{le}$ permitirá reconocer en la sociedad el mecanismo de «autopreservación y propagación de las especies (...), los grandes fines que se impone la naturaleza». El mercado parece satisfacer cada uno de los requisitos:

1. Amoralidad. Para obtener el bien(estar) social el mercado no necesita ninguna autoridad que aleccione a las gentes a seguir cierto tipo de vida. En el mercado las penalizaciones que hacen más atractivas unas opciones que otras y que castigan la elección errada, no requieren ni de instancias morales ni de agentes sancionadores. El consumidor que cambia de producto no quiere penalizar al productor. No forma parte de su horizonte intencional, aunque sea resultado de su acción. A diferencia de lo que sucede en muchos proyectos sociales cooperativos, que dejan sin resolver el problema de quién asume el costo de la coordinación, en el mercado existe un sistema descentralizado y no intencional en donde los individuos se deben comportar de tal modo que con su acción castigan a quien no se comporta como debe, sin que para ello tengan que informarse de quién se trata ni pretenderlo ${ }^{20}$.

2. Armonia de objetivos. Los individuos se ven impelidos a realizar aquella conducta que coincide con los objetivos comunes sin requerir para ello de un compromiso normativo. No tienen los fines de la sociedad, pero el mecanismo del mercado se encargarâ de asegurar que al perseguir sus propios objetivos apunten en la misma dirección que el objetivo social. Andando el tiempo, la maniobra de disolución del cimiento normativo de la sociedad buscará completarse en una doble dirección. Primero, hacia abajo, cuando se intente mostrar que la única conducta posible, el egoísmo, es àdemás, la natural, la única que proporciona ventajas adaptativas ${ }^{21}$. Hacia arriba, extendiendo la tesis de Hume, según la cual «el respeto por el interés público no constituye nuestro motivo primordial para respetar las reglas de justicias ${ }^{22}$, se reescribirán las instituciones sociales, los principios normativos, las relaciones interpersonales o los escenarios políticos como lugares de negociación e intercambio ${ }^{23}$.

3. Carácter algoritmico, el que mejor detecta la imagen de la «mano invisible». Más altá de las motivaciones de los individuos, la lógica de la competencia impone una suerte de fatalidad que desencadena wheneficiosos efectos». En este extremo, la clásica comparación entre la mano invisible y la selección natural, tan limitada en tantos aspectos, apunta con corrección a los rasgos de esos procesos con designio pero sin artífice propios de un algoritmo: a) independencia del soporte sobre el cual se realiza, b) ausencia de inteligencia de los constituyentes respecto al proceso del 
cual forman parte, c) resultados garantizados ${ }^{24}$.

4. Estabilidad reproductiva, garantizada en el mercado por los diversos procesos que coinciden en reproducir y alimentar aquel tipo de comportamicnto que hace funcionar al mercado. El sistema produce los comportamientos que aseguran su reproducción. Ello es resultado del particular tipo de estímulos y penalizaciones que aseguran que lo que los individuos quieren es lo que deben querer. No parece haber un modo mejor de garantizar la reproducción del escenario, la «fuerza vinculante»: «la mejor seguridad para garantizar la fidelidad de la humanidad es que coincidan el interés y el deber ${ }^{25}$.

Así las cosas, la tentación de presentar al mercado como un mecanismo capaz de proporcionar una solución a la DS es dificil de resistir. El mercado constituiría un sólido cimiento (laico) a la vida colectiva sin necesidad de extrañas comuniones morales, compromisos civicos infatigables o competencias discursivas más allá del alma y ta paciencia humanas. Desdichadamente, ante una mirada más atenta, resulta discutible que el mercado satisfaga los requisitos societarios. Mejor dicho, al no satisfacerlos todos, la satisfacción parcial resulta particularmente dañina: unos apuntan contra otros y los resultados son desastrosos para el propio escenario que, en principio, estaba intentando cimentar. Son desastrosos por ineluctables.

\section{El mercado contra la disposición societaria}

El mercado, para su funcionamiento, necesita una red moral e institucional, unas precondiciones sociales y normativas ${ }^{26}$. Ese marco cívico permite respetar los contratos, aceptar los compromisos, realizar los intercambios o asignar derechos. Para que el mercado resuelva la DS ha de estar en condiciones de asegurar un fundamento a la sociabilidad desde el principio, esto es, también a ese marco cívico. Sin embargo, el carácter ciego e inflexible del mercado socava las precondiciones cívicas de funcionamiento del escenario social. Aquellos marcos institucionales, las leyes que aseguran la propiedad, sin ir más lejos, son bienes públicos ${ }^{27}$, bienes que el mercado por sí mismo es incapaz de suministrar. Pero no sólo se trata de bienes públicos. En virtud del inevitable desajuste temporal que se da entre los actos de compra y venta, el más sencillo de los intercambios de bienes privados resultaría imposible sin algún vínculo moral ${ }^{28}$. Si el mcrcado se quiere una genuina garantía frente a la DS, es obligado que esos mismos escenarios no sean ajenos al mercado. Más exactamente, la tesis del mercado como motor inmóvil de la cohesión social ha de estar en condiciones de mostrar que esas precondiciones: a) son producto del mercado, y b) ven asegurada su reproducción por el mercado.

1. La primera de las tareas constituye buena parte del programa de investigación de las teorías de elección pública; en particular, de la teoría económica de la democracia ${ }^{29}$. En esencia, el programa consiste en diseñar escenarios políticos que funcionan al modo de los mercados económicos con los partidos compitiendo por votos. Los políticos, al procurar su beneficio, tendrían incentivos para averiguar y atender las demandas de los votantes/consumidores. De cse modo, al perseguir su interés, actúan en «coincidencia con su deber». Así las cosas, el sistema produce el bien(estar) público sin presumir virtud en los individuos. Es más, para funcionar ni siquicra necesita identificar a los ciudadanos virtuosos. Lo malo es que tampoco está en condiciones de hacerlo. No sólo eso, sino que reprime la virtud. $Y$ sin virtud, no hay institución que funcione: tampoco el mercado político. 
La teoria del diseño institucional arranca con dos principios, referidos a la identificación de las motivaciones: un principio de realismo de la virtud, según el cual, los individuos no procuran el interés público por sí mismo, y un principio de posibilidad de la virtud, según el cual las instituciones no deben diseñarse de tal modo que socaven las motivaciones públicas ${ }^{30}$. Hay razones poderosas para el segundo de esos supuestos, también en el caso del mercado político. Este presenta dos características que hacen importante la presencia de la virtud. Por una parte, hay un problema general de libertad en la elección y decisión de objetivos y tareas por parte de los políticos que hace que sean justamente aquellas labores públicas que requieren de la virtud las que mayor espacio dejan para la discrecionalidad, para que los agentes egoístas obtengan beneficios. Por otra parte, hay un problema de información (de agente-principal) que está en la base misma del mercado político ${ }^{31}$. Al delegar la gestión en un político profesional, precisamente porque adquiere los servicios de alguien que se «informe y actúe», el votante no tiene modo de conocer si la acción emprendida es realmente la que le beneficia ni, tampoco, si la ejecución es la mejor. En ese escenario, cuando los politicos se ven abocados a regirse por su interés, a explotar las oportunidades de beneficio, los buenos resultados se hacen imposibles. En suma, aun si el mercado, o para ser exactos, el muy limitado caso del mercado con excepcionales circunstancias de producción e información ${ }^{32}$, no requiere la virtud o la confianza, lo cierto es que el «mercado político», el conjunto institucional que permite el funcionamiento del mercado, sí to requiere. El problema es que lo que necesita no es lo que produce: el mercado político sólo reconoce la motivación del egoísmo.

2. De todos modos cabría replicar que, aun si el mercado no está en condiciones de asegurar aquellas condiciones, sí que está en condiciones de reproducirlas. Del mismo modo que la norma de conducir por la derecha tiene un origen puramente circunstancial que nada tiene que ver con las razones de su mantenimiento, podría suceder que el respcto a las promesas, aún si tiene una raíz religiosa, una vez en circulación, su propia utilidad social asegure su reproducción. De modo que se trataría de fijar esas precondiciones políticas, desde alguna instancia previa (moral o no) al propio mercado, y después dejar a éste todo lo demás, incluida su reproducción. Esa propuesta presume la posibilidad de compartimentacion, de construir un escenario desde la cooperación y la virtud para el mejor desarrollo de la actuación de la mano invisible, escenario que se mantendría ajeno al funcionamiento de ésta. Sin embargo, también aquí hay dificultades. En primer lugar, las derivadas de la virtud algorítmica del mercado. La «exposición» al mercado y a la conducta egoísta alienta el egoísmo más allá de sus lugares de beneficio original. La experimentación psicosocial muestra que los economistas son más egoístas que el resto de la población y que los estudiantes de microeconomía, el hábitat natural del homo oeconomicus, se vuelven más egoístas en el curso de sus estudios ${ }^{33}$. Otro tanto sucede con otra virtud del mercado, la amoralidad con la que se mantiene la coordinación social. Sucede que aquellos comportamientos (cooperación, confianza, veracidad, participación voluntaria) que permiten solventar problemas de acción colectiva (el escenario público) se ven minados por las estrategias de conducta que alimentan los mercados ${ }^{34}$. En virtud de su sistema de incentivos, el uso generalizado del mercado en la asignación de trabajo y mercancías da pie a una serie de problemas de acción colectiva que socavan cualquier forma de acción cooperativa. Un conjunto de procesos (disminución de los vínculos comunitarios, menor duración esperada de las interacciones sociales, incremento de la tasa de 
preferencia temporal) derivados de la propia falta de cimiento normativo en las interacciones sociales de mercado hace que, al aumentar los costos de la cooperación y los beneficios de la defección, buena parte de las interacciones tomen la forma de un dilema del prisionero, circunstancia que alienta el comportamiento free rider y mina la producción de los bienes públicos que hacen posible el escenario moral del mercado. En el contexto de conductas propiciadas por el mercado, el aumento del coste de proporcionar bienes públicos hace menos atractivas las estrategias cooperativas. Así, por cjemplo, el costo de proporcionar bienes públícos depende en buena medida de la disposición de los que participan en su suministro para comprometerse en procesos de suministro de información, deliberación y toma de decisiones.

Parece, pues, razonable pensar que el mercado no sólo no propicia los escenarios cívicos que hacen posible el mercado, sino que, por su propia dinámica, tiende inexorablemente a socavarlos. Sin embargo, persiste el reto de encontrar algún mecanismo que realice las funciones que el mercado parecía cumplir pero que no cumple. Dos han sido las respuestas más frecuentes. La primera apela a un cemento civico derivado del compromiso que los ciudadanos tienen con las decisiones que adoptan en unas optimas condiciones de diálogo. La segunda invoca un cemento emocional, un conjunto de disposiciones afectivas que aseguran el vinculo social.

\section{El vinculo civico}

Una socjedad en la que los individuos se comprometen con unas condiciones básicas de diálogo arrastraría, en virtud de la propia dinámica de la argumentación pública, a un compromiso con los resultados de ese diálogo. Ése es el núcleo que comparten diversas teorías que, sin embar- go, discrepan en casi todo lo demás ${ }^{35}$. En las formulaciones más refinadas se establece una fuerte conexión entre deliberación, racionalidad e interés público: en la deliberación, la defensa pública de las opiniones obliga a los ciudadanos a suscribir criterios impersonales de accptabilidad (de las mejores razones) $y$, con ello, a admitir la posibilidad de estar equivocados y de modificar opiniones y preferencias. Ese núcleo sería suficiente para excluir pragmáticamente las invocaciones al propio interés y al destructivo free rider. En el límite, en el diálogo, uno puede «preferir que los otros tengan razón» porque a la postre, para decirlo de nuevo con Borges, «un diálogo es una investigación y poco importa que la verdad salga de uno o de boca de otron.

Sin duda se dan ciertos vínculos entre deliberación y fuerza motivacional que apuntan en la dirección de los requisitos de estabilidad. Es innegable que los individuos se pueden sentir comprometidos con aquello en cuya elaboración han participado y en ese sentido se satisface algo parecido al requisito de armonia ${ }^{36}$, aun si tampoco cabe ignorar otras circunstancias que invitan a matizar el alcance de aquel vínculo ${ }^{37}$. En todo caso, en los términos expuestos, la perspectiva deliberativa aparece únicamente como una teoría (epistémica) de la justificación de las decisiones (democráticas): las decisiones democráticas estarían justificadas porque se basan en procedimientos correctos que aseguran el triunfo de las mejores razones. Pero nada dice dicha perspectiva sobre la fuerza vinculante de las decisiones $y$, mucho menos, sobre los diversos requisitos de estabilidad ${ }^{38}$. No hay que confundir la justificación con las condiciones de funcionamiento. No es lo mismo la fundamentación (las condiciones epistémicas) de la democracia que la exploración de las condiciones de su funcionamiento (la teoria de la democracia), del mismo modo que hay que distinguir, mal que le pese a la 
filosofía de la ciencia construccionista, entre las reglas que los científicos utilizan en sus inferencias, la justificación epistémica, y las reglas que rigen las comunidades cientificas (comunismo, escepticismo organizado, publicidad de los argumentos, etc.) ${ }^{39}$. Precisamente porque no cabe confundir ambos planos es por lo que cobran importancia las condiciones de funcionamiento del escenario deliberativo, la ontologia social que permite "realizar" la deliberación, la estabilidad, en suma.

La despreocupación por las condiciones de funcionamiento resulta particularmente nítida en aquellas versiones de la democracia deliberativa que trazan una radical separación entre el mundo de la producción/economía, regido por el interés y la negociación, y el de la política, que atendería a la razón y la deliberación. Separación bastante discutible a la luz de la dinámica destructora de la vida cívica por el mercado. En ese terreno, el terreno de la DS, resultan más vigorosas las tcorías (republicanas) de la democracia deliberativa que buscan entroncar con el humanismo cívico florentino ${ }^{40}$. Por lo pronto, proporcionan una solvente respuesta al requisito de la armonía o continuidad entre los intereses individuales y los intereses colectivos. Para ello arrancan con una tesis fáctica que invierte la dirección de la secuencia causal de la mano invisible. Mientras para el mercado, al procurar su beneficio, los individuos producían, sin pretenderlo, el bien común, para el republicanismo, el mejor modo de defender la propia libertad es defender la libertad de todos. Cuando los ciudadanos quieren asegurar su independencia, escapar a la arbitraricdad real o potencial de los demás, tienen que participar en la vida pública y asegurar el imperio de la ley. De otro modo, estarán al albur de los poderosos. Es a través de la ley justa, resultado de la participación y la deliberación, como se asegura la libertad. No sólo eso. Una sociedad política que garantiza desde el terri- torio público - desde la ley- la libertad de cada uno, tiene que asegurar ciertas condiciones de independencia en la formación de juicios y en las condiciones de vida de los ciudadanos, condiciones siquiera mínimas de igualdad que impidan, por ejemplo, dependencias materiales específicas entre ciudadanos ${ }^{41}$. En esas circunstancias es fäcil que surja una sólida disposición cívica, con ciudadanos responsables, que proporciona un buen fermento para solventar los problemas de coordinación y de obtención de bienes públicos ${ }^{42}$.

La perspectiva cívica proporciona una atractiva caracterización de la vida colectiva $y$, en la medida en que se sustenta en argumentos epistémicos, acerca de los escenarios deliberativos como un lugar de cristalización de las correctas condiciones en la formación de los juicios y de triunfo de las mejores ideas, lo hace sin ninguna subordinación normativa. Cuando se acompaña de una teoría política que establece una relación causal entre la libertad de todos y la libertad de cada uno sugiere, además, la existencia de un mecanismo con algunos de los requisitos de estabilidad. Sin embargo, está lejos de proporcionar una respuesta completa a la DS. Se podría decir que la DS no es el problema de la perspectiva cívica, pero, por lo mismo, la perspectiva cívica tampoco es la solución a la DS, aunque ya es bastante, desde luego, que no se adivinen los rasgos destructivos hacia el escenario cívico que se adivinaban en la «mano invisible».

Aun si la perspectiva cívica parece insertarse bien en una red moral que requiere leyes, confianza, bienes públicos ${ }^{43}$, lo cierto es que el vínculo de los individuos con la república, con la defensa de la vida cívica, como un instrumento para asegurar su propia libertad, es circunstancial y está sometido al albur de que los ciudadanos no se interesen por su libcrtad. Si la vocación cívica es un instrumento, es que, después de todo, los individuos no tienen una genuina disposición societaria. Aunque 
pueda ser improbable, no se descarta que el individuo se reserve elegir la participación en el juego social, no se descarta la posibilidad de una identidad presocial, de un lugar precívico desde donde se calcula y decide entrar en diálogo y razones. Esa simple posibilidad, que resulta irrelevante y acaso inevitable en la fundamentación, en el terreno epistémico, complica cualquier intento de presentar a la perspectiva cívica como una respuesta satisfactoria a la DS. La fuerza vinculante de las decisiones o la misma estabilidad reproductiva parecen estar sometidas al humor de unos ciudadanos que ven su relación con el escenario público como un simple instrumento, aún si lo juzgan beneficioso ${ }^{44}$.

Mostrar las condiciones en las que se superan los problemas no equivale a superarlos. Afirmar que si los ciudadanos fueran deliberadores infatigables con un fuerte sentimiento civico y exquisita sensibilidad para la justicia, las cosas irían mejor, es sin duda más realista que la fábula del (equilibrio general de)mercado, cse mundo en competencia perfecta, sin tiempo, externalidades, bienes públicos, rendimientos crecientes o asimetrías informativas ${ }^{45}$. Sin duda es buena cosa saber que ciertos comportamientos que no resultan imposibles para los seres humanos aseguran un buen orden social, sobre todo si hay razones para pensar que ese orden social satisface, además, algunos requisitos de estabilidad. Pero con eso no basta. También hay que averiguar si el escenario tiene que ver con disposiciones bien asentadas, si cabe esperar que actúen las fuerzas que aseguran la reproducción social. Mientras en la conjetura de la mano invisible esa labor estaba asignada al egoísmo, en la sociedad republicana parece necesaria cierta disposición cívica, cierta disposición virtuosa ${ }^{46}$.

Sin embargo, el terreno de las disposiciones resulta bastante espinoso. Existe una razonable prudencia a realizar afirmaciones acerca de la naturaleza humana ante el temor de introducir de rondón compromisos con ideas (perfeccionistas) de bien que hagan imposible el agnosticismo normativo, Resulta comprensible ese temor, por más que haya razones para dudar de su pertinencia: tiene escaso sentido un proyecto social que ignore lo que sabemos acerca de cómo son los humanos. Al cabo, el requisito agnóstico se satisface tanto con un fundamento trascendental como con la investigación positiva, con la exploración naturalista. Circunstancia, por cierto, no ignorada por los defensores de la mano invisible que veían en el egoismo el cimiento natural donde afirmar la sociabilidad.

En ese contexto no han de extrañar los intentos de cargar la suerte y recuperar un republicanismo apegado a la naturaleza humana, al animal político con una natural disposición a la vida cívica ${ }^{47}$. Esos intentos han puesto un mayor acento en la virtud, en la importancia no sólo de la correcta acción, de la acción que tiene buenas consecuencias, sino tambiến en la correcta motivación, en hacer lo correcto por las acciones correctas, con las disposiciones correctas, incluidas las emociones correctas. Resulta evidente que para un comportamiento virtuoso resulta impensable la visión instrumental de la vida cívica y con ello se disipa el carácter del vínculo entre la acción del individuo y el interés público. La dificultad, obviamente, reside en la plausibilidad de la maniobra. Despejarla será cosa de la perspectiva emocional.

\section{El vinculo emocional}

Buena parte del atractivo del mercado radicaba en que las consecuencias de las acciones apuntaban en la dirección del interés general. No importaban las razones de cada cual. Desde esa perspectiva resultaba irrelevante, por ejemplo, la distinción entre que el bienestar de A aumente con el de $\mathrm{B}$ y que aumente por(que aumenta) 
el de B. Las motivaciones son ajenas al mercado y su funcionamiento ${ }^{48}$. Se ha visto que la estrategia civica llegaba a un resultado parecido. No era necesario distinguir entre quién procuraba el interés público para defender sus intereses y quién lo hacia por una auténtica preocupación cívica. Sin embargo, en el caso del mercado, también se ha visto que, cuando algún requisito deja de funcionar, la simplicidad motivacional del homo oeconomicus empicza a ser un problema ${ }^{49}$. El homo oeconomicus va, por así decirlo, a piñón fijo. Mientras existe continuidad entre sus intereses y el bienestar común, muy bien. Pero, cuando se da un desvío, no atiende a razones que no sean las suyas y se convierte en una suerte de adicto al dilema del prisionero que, en la mala senda, se enfila ineluctable hacia el desastre. Ya se ha visto cómo esa circunstancia tenía consecuencias desastrosas para la solución de la DS. Las cosas son algo mejores para la perspectiva cívica. Cuando los comportamientos convergen en la defensa del interés público, al menos hay lugar para quienes tienen una genuina disposición cívica, cosa imposible con la convergencia en el egoísmo impuesta por el mercado.

Sin embargo, aunque observacionalmente pueda parecer que no existen diferencias entre el ciudadano que se comporta del modo correcto por las razones correctas y el que no, lo cierto es que la diferente disposición es importante, también por sus consecuencias. No se trata únicamente de que hay algo que no funciona en el individuo que sc comporta de un modo correcto pero que no siente de un modo correcto, que teniendo razones para sentir, no siente. En ese sentido, las críticas de raíz aristotélica y del feminismo son absolutamente pertinentes ${ }^{50}$ : hay una incapacidad incluso para la correcta evaluación normativa, para reconocer la complejidad de los acontecimientos particulares, para identificar los principios morales relevantes en cada caso o para su aplica- ción, por no referirse a lo que tiene de repugnante un individuo que a contra vísceras sigue lo que dicta el deber. Pero hay algo más, que tiene que ver con las consecuencias, con las condiciones de posibilidad de la vida social: las emociones cumplen importantes funciones a la hora de resolver la $\mathrm{DS}_{2}$ al actuar como disposiciones para el compromiso que solventan problemas de coordinación social.

En perfecta lógica económica no tendría sentido iniciar un pleito por una estafa que resulte más costoso que la propia pérdida. Los débiles no deberían prolongar una negociación más allá del punto donde los costos superan a los posibles beneficios. La venganza supone riesgos y costos sin posibilidad de reparar el daño inicial. Sin embargo, para el funcionamiento de la vida social es importante que el estafador sepa que tengo la intención de llegar hasta los tribunales, que el poderoso conozca que aprecio mi dignidad o que quien me quiera dañar prevea mi lealtad con los míos. De ese modo, sc evita el robo, la barbarie o la injuria. El propio individuo se beneficia de su propio comportamiento «irracional», de su conducta honorable; de transmitir confianza, de su compromiso con la justicia, se hace posible la red moral del juego social. Las emociones, la capacidad para la indignación o la justicia, hacen que los compromisos resulten creibles ${ }^{51}$.

El modo como las emociones aseguran la coordinación resulta interesante. Por lo pronto, para que las emociones funcionen se requiere que no se elijan, que la acción que tiene los resultados correctos no se escoja por los resultados. La acción correcta desde las consecuencias lo es precisamente porque es la correcta desde los principios, porque no atiende a costos o beneficios. Su eficacia reside en su incondicionalidad. El que piense en causarme daño ha de saber que mi indignación no obedece a un cálculo que estoy dispuesto a revisar. Repárese en que la función de coordinación queda asegurada merced a un sofis- 
ticado juego de atribuciones intencionales: «el otro sabe que yo sé que él sabe...». Atribuciones que permiten que, aun si la amenaza no se formula, los actores conozcan que «puede pensarse». La emoción asegura la coordinación porque forma parte de su kentorno cognitivow: los individuos «comparten información sobre la información que comparten ${ }^{52}$. Se requicre, además, cierta coordinación entre emociones. La vinculación entre tu miedo y mi indignación, entre tu vergüenza y $\mathrm{mi}$ reproche, permite la solución de los conflictos sin romper el escenario social, sin que cada encuentro desencadene una guerra sin tregua. Mi reproche funciona porque tú experimentas la vergüenza. Las emociones, finalmente, no requieren en los individuos conocimiento de las consecucncias sociales (benéficas) del juego emocional, de su función coordinadora ${ }^{53}$. El juego emocional es ajeno al designio al que sirve.

Las emociones proporcionan un soporte a la resolución de la DS, un cimiento «trascendental» respecto a territorio normativo, pero no metafísico. No faltan resultados de la etología o la neurobiología que muestran cómo aseguran la coordinación, evitan el conflicto y hacen posible la valoración moral. Las emociones aparecen en el curso de la evolución, asociadas a procesos de socialización y cerebración, hasta alcanzar altos grados de complejidad (emociones sobre cmociones) en las especies con mayor desarrollo cerebral. La investigación neurológica ha mostrado la localización de la sensibilidad emocional en ciertas áreas del cerebro, su relativa autonomía respecto a otras funciones cerebrales y los vínculos con la racionalidad y la moralidad. Los individuos con ciertas lesiones cerebrales, que se muestran incapaces de calibrar el significado emocional de las situacioncs, son, a la vez, incapaces de realizar evaluaciones morales completas ${ }^{54}$. Saben cómo hay que comportarse, qué es lo que corresponde hacer en cada caso o qué se sigue de cada curso de acción, pero son incapaces de valorar las acciones. Convierten, por asi decir, las normas morales en normas de etiqueta. Tales individuos (o monos a los que se les ha cortado la conexión entre la amígdala y el neocórtex) se muestran incapaces de dar respuestas emocionales y al final resultan inútiles para la vida social. Con la sensibilidad cmocional desaparecen la capacidad para la empatía y las bases mismas de moralidad.

En suma, las emociones proporcionan un terreno, con base neurológica, indiscutible funcionalidad adaptativa $y$ estrechos vínculos con la racionalidad cognitiva y práctica, donde afirmar la solución a la DS ${ }^{55}$. No requieren fundamento, como no requieren fundamento la visión $\mathrm{o} e l$ habla. Sencillamente se está ahí, se empieza desde ahí. Del mismo modo que estamos instalados en la racionalidad, estamos instalados en la capacidad emocional que afirma el territorio de la moralidad social. En ese terreno se está, no se elige ${ }^{56}$. No está somctido a un cálculo y, por lo mismo, no está sometido a las debilidades de las teorías de la moral como negociación. Estas, eficaces frente a los procesos de coordinación, al mostrar la posibilidad de los equilibrios de convención o las ventajas de las normas, se veían perpetuamente amenazadas por un free rider, que podía decidir romper los equilibrios, no jugar. Los agentes del Rational Choice vienen a ser como los individuos con lesiones en la corteza prefrontal, individuos que entienden las normas morales como convenciones, individuos incapacitados para la vida social. Ahora podemos recuperar los resultados que muestran la funcionalidad de las normas, recuperar los sugestivos resultados de la teoría de juegos que muestran cómo resultan ventajosos para los individuos la emergencia de ideas como las de compromiso o justicia, o las ventajas de las convenciones, sin necesidad de explicar las normas por sus consecuencias (fa- 
Lacia funcional) y sin los problemas de explicar la reproducción de las normas apelando a una capacidad de previsión más allá de la mente humana. El escenario último de la moral social no es una elección, sino una disposición. El cimiento emocional está en los individuos y es bueno para todos. Que no se elija es precisamente lo que requiere el buen funcionamicnto del escenario. Los individuos hacen lo que deben hacer.

El territorio emocional no aparece como la disolución de la ética pública. Sencillamente es su condición de posibilidad. No se trata de reducir las teorías morales a un capítulo de la teoría de las emociones. Hay un abismo de sutileza entre moralidad y emociones. Las emociones proporcionan repertorios poco flexibles, lo que se aviene mal con elementales criterios de racionalidad y moralidad, criterios que reclaman valoraciones ceñidas a escenarios cambiantes y valores en conflicto. La emoción que en cicrto momento pudo resultar ventajosa, en otras condiciones puede conducir directamente a la catástrofe. De hecho, su aparición en el curso de la selección natural está asociada a los procesos más tempranos de cerebración. Por otra parte, las propias emociones pueden ser objeto de valoración, por su adecuación o por su basc cognitiva. Una emoción puede ser excesiva o inapropiada dadas las circunstancias o puede corregirse cuando se dispone de nueva información. Pero nada de eso mitiga su funcionalidad a la hora de asegurar el vínculo social. También cometemos errores inferenciales sistemáticos en ciertos contextos, y también percibimos incorrectamente muy conocidas imágencs de los psicólogos, pero ello no nos hace dudar del carácter adaptativo de la racionalidad o de la visión ${ }^{57}$. Al cabo, nuestra física 《intuitiva» (aristotélica) es susceptible de ser valorada: es falsa ${ }^{58}$.

\section{El instinto social}

La estrategia de la "mano invisible» pretendia mostrar que la DS desaparece sin que se pretenda cuando cada uno va a la suya. Pero ya se ha visto que lo menos que se pucde afirmar es que ese vínculo entre egoísmo y (buen) orden es contingente. No sólo eso. De hecho se acaba de ver que hay bastantes razones para invertir el mecanismo. Resulta beneficioso scr honesto. En ese sentido, las teorías acalculadoras" de la moral tenían razôn. La moral parece salir a cuenta. En un doble sentido, para el individuo y para la sociedad. Doble sentido que se corresponde con dos estrategias falaces muy frecuentes en las teorías que relacionan la explicación de las normas con sus beneficios ${ }^{59}$. La primera, común entre economistas, se traduce en un abuso de la intención y consiste en atribuir la existencia de la norma a los individuos que se benefician de ella ${ }^{60}$. El expediente más frecuente consiste en acabar encontrando siempre al final un egoísta omnisciente que se beneficia de aquello que se pretende explicar. Los muchos problemas de cstc proceder se mucstran particularmente nítidos en la explicación de la disposición moral, que, por definición, no puede ser elegida. Es muy posible que la cooperación o la honestidad pucdan salir a cuenta, pero para que ello suceda han de ser auténticas (o sentidas). En el momento en que se es honesto instrumentalmente, por cálculo, los beneficios se disipan. La virtud o la disposición al compromiso se han de sedimentar, por así decir. La otra estrategia (la falacia funcional, de hecho) consiste en explicar las normas por sus consecuencias benéficas para algún escenario en el que se inserta. Es un proceder muy frecuente entre sociólogos, aunque se da también entre economistas que explican las normas por sus uexternalidades positivas" ${ }^{61}$.

¿Hay algún modo de recuperar la solución a la DS propuesta sin incurrir en estas 
dos falacias? Si así fuera, no se puede descuidar la importancia de un resultado que, cuando menos, permitiría rescatar las "ventajas» (coordinación) de la moralidad detectadas por las teorías económicas de la moral ${ }^{62}$. Se requiere, además, por lo dicho, para asegurar la estabilidad reproductiva, que el comportamiento que alimenta el mecanismo no sea mudadizo, cosa de unos pocos o sometido a *cálculos». La ünica solución en condiciones de satisfacer los requisitos de espontaneidad, universalidad, naturalidad y estabilidad, tiene que ser, obviamente, biológica. El "instinto" no está sometido a elección ni es fluctuante ${ }^{63}$. De hecho, si hubiera algo así como un «instinto de la virtud» ${ }^{64}$, el problema «liberal» de la fundamentación (agnóstica) desaparecería. Al cabo, nadie pretende fundamentar la visión o justificar el lenguaje ${ }^{65}$. Como ha mostrado hasta la fatiga la discusión acerca de los fundamentos de la inducción, hay una dificultad de principio en este tipo de justificaciones trascendentales empeñadas en derivar $x$ (moralidad, necesidad lógica) de algo que no tiene $x^{66}$. Por supuesto, no se trata de resolver el expediente de la DS mediante el oportuno gen ${ }^{67}$. Los procesos cooperativos son diversos (altruismo recíproco, parentesco, selección de grupo, byproduct mutualism $)^{68}$ y las explicaciones que pueden valer para las hormigas no valen para los homínidos con importantes procesos de encefalización. La vocación social de éstos es una tarea compleja que compromete estructuras diversas. Del mismo modo que el lenguaje requiere ciertas reglas de fonologia, de sintaxis, de producción de habla $\mathrm{y}$ de descodificación sonora, la disposición societaria reclama un proceso múltiple (un diseño adaptativo complejo) que exige una coordinación de funciones que no cabe atribuir al puro azar. Ese proceso, que a Adam Smith le podia parecer diseño, sólo cabe entenderlo en términos de selección natural.
Los problemas de la interacción social comprometen circuitos cerebrales especializados resultado de un proceso adaptativo, módulos como los comprometidos en el lenguaje, el reconocimicnto de caras o la construcción visual de escenas ${ }^{6}$. En el pleistoceno, en grupos con alto grado de estabilidad, con individuos con largos períodos de maduración, con períodos improductivos y convivencia de miembros de distintas generaciones, la predicción de la conducta de los otros presentaba indiscutibles ventajas adaptativas. En esas condiciones resultaba importante «realizar inferencias sobre sus actitudes, motivos, y anticipar su futura conducta» ${ }^{70}$. Los individuos se configuran como «psicólogos naturales» que se atribuyen intenciones a las que dan respuestas, se asumen como individuos y adquieren conciencia reflexiva; tienen, en suma, una teoría de la mente. La colaboración requiere de la atribución de intenciones, pero, a la vez, está sometida, por esa misma circunstancia, al peligro de la aparición del engaño, del comportamicnto free rider que la socava. $\mathrm{La}$ comunicación es un ejemplo bien conocido. Se basa en la expectativa de la colaboración, en la presunción de que el otro transmite con veracidad, brevedad, claridad y orden, El oyente asume que la información es relevante, no le es conocida y está suficientemente relacionada con lo que conoce como para realizar esa inferencia que es la comunicación, inferencia que le permite interpretar las intenciones del otro, eliminar ambigüedades, ordenar informaciones parciales y completar fragmentos (pronombres, alusiones, ctc.) ${ }^{71}$. En ese contexto, es fácil que se dieran algoritmos darwinistas reguladores de la interacción social, capaces, por una parte, de procesar los costes y beneficios de la interacción social, y, por otra, de realizar inferencias complejas sobre las posibles trampas de los free riders. Lo cierto es que hay la suficiente evidencia experimental para hacer plausible la conjetura de que cxiste 
un fuerte vínculo entre racionalidad, interacción social e identificación de los «mentirosos» ${ }^{72}$. Los individuos aplican reglas inferenciales correctas con suma facilidad en escenarios de reciprocidad, inferencias que permiten reconocer el fraude. Para que pueda evolucionar la disposición societaria se requiere un aparato cognitivo bien dispuesto para detectar a quienes rompen los contratos. Sólo quien inspira confianza puede obtener las ventajas de la cooperación, pero eso sólo lo pueden hacer, enfrentados a «detectores de mentirasos», quienes son de confianza ${ }^{73}$.

La idea de circuitos mentales cvolucionados especializados en los problemas de la interacción social no es extraña ni excepcional. "Las inferencias necesarias para detectar mentirosos son obvias para los humanos en el mismo sentido en el que las inferencias necesarias para la ecolocalización son obvias para los murciélagos ${ }^{74}$. Se trata de circuitos desarrollados para resolver los problemas de la cooperación, presente en todos los humanos, sin necesidad de consciencia, instrucción formal y aplicados sin conocimiento de la lógica subyacente. Esos circuitos fijan en nosotros conceptos y motivaciones que hacen posible el juego intencional. Sobre ellos se asienta la interacción y el sustrato emocional. "No sólo facilitan el desarrollo de la cooperación, también hacen posible la amenaza y el funcionamiento de la venganza.» El jucgo emocional depende «de la naturaleza de la máquina interpretativa de la especie... Si el otro animal es incapaz de categorizar las acciones que desencadenen su daño, el castigo resulta inútil » ${ }^{75}$. La evidencia de ese funcionamiento es también negativa: los autistas, que carecen de la capacidad de representarse las representaciones mentales de los otros, de «una tcoría de la menten, se muestran también incapaces para comprender el significado normativo de los acontecimientos $y$, aun si son «inteligentes», resultan particularmente indefensos socialmente.
La naturalización de la DS no equivale a la disolución de la discrepancia o la diversidad. Es cierto que «la diversidad cultural ha sido siempre invocada como prueba de la plasticidad de la especie humana», pero no faltan razones para creer que «los organismos dotados de una mente verdaderamente modular pueden engendrar culturas auténticamente diversas» ${ }^{76}$. La diversidad es tan natural como la sociabilidad. No cabe ignorar la importancia para las teorías normativas de un programa ${ }^{77}$ capaz de asegurar una base naturalista a la diversidad: se «disuelve» la DS sin dejar de reconocer «el hecho del pluralismo».

\section{Para acabar}

En las páginas anteriores se han visto razo. nes para, por lo menos, revisar la perspectiva liberal sobre el problema de cómo es posible el orden social. En el camino se ha sugerido la conveniencia de revisar un par de axiomas liberales, que mucho tienen que ver con el «problema» y su «solución», el mercado. El «problema» tiene mucho que ver con una insostenible idea de individuo presocial que ha persistido en el liberalismo más genuino. Sencillamente, no hay lugar para la pregunta inaugural de la "fundamentación" del contrato social que está en la base del liberalismo. Del mismo modo que, si es el caso que el universo es finito, carece de sentido preguntarse acerca de qué hay fuera, tampoco cabe preguntarse por qué los individuos están en sociedad. Por supuesto, en ese estar en sociedad intervienen disposiciones diversas. No se trata, pace Ridley, de que exista una línea directa entre un gen y el tacherismo ${ }^{78}$, como no hay un lazo entre genes y una lengua, aunque lo hay con la capacidad para adquirir una lengua. El juego de lo posible no empieza desde ninguna parte. No elegimos la sociabilidad, como no elegimos el lenguaje. 
No sólo eso. Aun si nuestras disposiciones son más informativas, si apuntan en una dirección, si, por ejemplo, hay una predisposición hacia el adulterio o la violencia, de ahí no se sigue la bondad o la ineluctabilidad del comportamiento. Primero porque sigue intacto el trazo entre lo positivo y lo normativo. Sucede en el terreno epistémico, en donde estamos en condiciones de corregir nuestros juicios y aun sesgos inferenciales errados por más sistemáticos que sean, con más razón en el normativo. Después de todo, curar una enfermedad genética es tambiến corregir una disposición en nombre de lo que nos parece bien. Segundo, porque también los buenos valores son «naturales», también se asientan en otras disposiciones que intervienen corrigiendo $\mathrm{y}$ ucontrabalanceando» ${ }^{79}$, pues, como dejará dicho D'Holbach, «las pasiones son los verdaderos contrapesos de las pasiones (...). La educación es el arte de sembrar y de cultivar en el corazón de los hombres las pasiones favorables" $8 \mathbf{8}$.

En el camino también se ha rectificado otra tesis liberal según la cual el interés, en el escenario de mercado, es la garantía del orden social. En cierto modo se podría decir que hay razones para invertir el trayecto que llevó de las pasiones a los intereses como garantía del orden social ${ }^{81}$. La convicción de que, para el incipiente pen- samiento liberal, la única justificación de la religión era su capacidad para disciplinar unas emociones que se entendian como fuente de desorden: los intereses, por una parte, permitían edificar un orden laico que sustituyese al orden religioso necesario para disciplinar a unas pasiones que se desbordaban y, por otra, por lo mismo, permitían anticipar al otro como no podían hacerlo las emociones. La ventaja del interés y del mercado es que hacían posible embridar las pasiones y asegurar el orden sin necesidad de intervenciones extrañas. El camino seguido hasta aquí ha sido un retorno. Son las emociones y el «instinto» social los que disciplinan un interés ( $y$ un mercado) de indiscutibles consecuencias desintegradoras. Circunstancia que no se le escapó a A. Smith, quien glosando a Hutcheson escribe con aprobación: «(La Naturaleza) actúa aquí (con el sentimiento de aprobación) como en otros casos con estricta economía... (Ese sentimiento) no está fundado en el egoísmo ni tampoco en una operación de la razón. No cabe sino suponer que se trataba de una facultad con la que la Naturaleza dotó a la mente humana (al igual que) sucedió con el sentido moral, el sentido público, o la vergüenza y el honor... (Ese sentimiento) se basa en un poder de percepción, análogo a los sentidos extemos» ${ }^{82}$.

\footnotetext{
- Fsa tensión es central en el ensayo inaugural de la moderna filosofia política, J. Rawls, A Theory of Justire, Cambridge, Harvard U. P., 1971. Baste con ver que el egoismo, que aparece implícitamente como una de las circunstancias materiales de justicia, es excluido por las cinco condiciones formales de justicia (Pp. 125-126). En ese sentido resulta llamativo que Rawls, que dice seguir a $D$. Hume, se cuide mucho de referirse al egoismo como tal entre las circunstancias de justicia, cuando lo cierto es que el escocís es absolutamente claro: ael origen de la justicia se encuentra únicamente en el egoísmo y la limitada generosidad
}

de Ios hombress, A Treatise of Human Nature, Oxford, Clarendon Press, 1975, p. 495.

2 J. F. Spiz, The Concept of Liberty in \&A Theory of Justice", Ratio Juris, 7, 1994.

"D. Gauthier, Morals by Agneement, Oxford, Oxford U. P., 1986, cap. 4. Para criticas, D. Hausstman, «Are Markets Free Zones", Philosophy and Public Affairs, 3, 18, 1989; F. Ovejero, Mercado, ética y economia, Madrid, Fuhem/lcaria, 1994.

+ Circunstancia, por cicrto, bastante desatendida por tradiciones radicales que han pasado en pocos años de ver la lucha de clases por todas partes, a una cándida 
e idealista fascinación por el poder de las buenas razones, fascinación que, por lu demảs, no resiste el análisis de los procesos psicológicos de formación de las creen. cias. Cfr. F. Ovejero, aEl ingreso universal y los requisitos de los proyectos emancipatorios", R. Lo Vuolo (comp.), Contro la exclusión, B. Aires, Miño y Dávila, 1995; "Democracia de mercado y ética ambiental», $\mathrm{Cla}$ " ves de la razón práctica, 68, 1996.

* J. F, Spiz, La hiberte politique, París, PUF, 1995.

- La estabilidad (entendida como aquella situación en la que el sistema epone en juego fuerzas propias de tal modo que vuelva al equilibrio después de perturbaciones*, p. 457) es la preocupación central el capitulo VII de $A$ Theory of Justice. No sólo eso, alli apunta un explicito intento de fundamentación naturalista (en las emociones, en el desarrollo psicológico) de los principios de justicia y de la propia estabilidad de la justicia como imparcialidad a ta luz de steyes psicológicas» (pp. 462, 476, 485,490) que será abandonado en Political Liberalkm (N. York, Columbia U. P., 1993), aunque se mantiene la centralidad de la estabilidad [ (la justicia como equidad) adopta como su idea fundamental la sociedad como un sistema equitativo de cooperación a lo largo del tiempo, de una generación a otran, p. 15] y la prencupación porque los individuos puedan estar interesados en -omprometidos con- soluciones que se juzgan las mejores desde algún punto de vista colectivo (o imparcia) Resulta interesante que el abandono de la perspectiva naturalista se acompañe de la modificación de las tesis de $A$ Theory por crecrlas subordinadas a una concepción "comprensivas del bicn, concepción incompatible con el respcto al whecho del pluralismos, y su sustifución por la concepción politica de la justicia que busca asegurar que di vinculo social se mantiene sin depender de una idea particular de bien.

${ }^{7}$ Críticas, por ejemplo, de P. Jones, R. Dworkin, O. ONeil; cfr. F. Ovejero, «La diáspora liberals, Claves de la razón práctica, 79, 1998.

" Por lo demás, no hay que olvidar que las teorías liberal-contractualistas empezaban por destacar que «si todo el mundo sintiera afecto por todo el mundo (...) la justicia y la injusticia no serian conncidas por los hombres» (D. Hume, op. cit., p. 495), para, inmediatamente después de reconocer la escasa plausibilidad de esa presunción, construir sus «contratos sociales», descalificados por la crítica comunitaria por irreales.

T. Schelling, Micromotives and Macrobehavior, N. York, W. Norton, 1978, cap. 4.

${ }^{10} \mathrm{El}$ núcleo compartido es el análisis en términos de interacción estratégica entre agentes racionales. Desde ahí hay diversidad de modelos: equilibrios de mercado, acción colectiva, negociación, etc. Tres clásicos desde tres disciplinas: D. Gatuthier, op. cit; J. Coleman, Foundations of Social Theory, Cambridge, Harvard U. P., 1990; y R. Posner, Economic Antysis of Law, Little, Brown and Company, 1986.

"J. Roemer, "The mismarriage of bargaining theory and justice distributive», Ethics, 97, 1986; J. L.
Colcman, Markets, Morals and the Law, Cambridge, Cambridge U. P., 1988.

${ }^{12}$ No es menos cierto que sin las pequeñas mentiras (sbuenos dias", "me alegto mucho", etc.) la vida social sería imposible.

13 Un cquilibrio de Nash. En otras lineas de argumentación, la norma aparece como una externalidad positiva (Coleman) y los principios de justicia (diş. tributiva) como aquellos que aseguran que la máxima concesión relativa exigida por ellos sea la más pequeña (Gauthier).

1* Por ejemplo, el dilema del prisionero. Vale la pena destacar: a) el carácter autorrealizador de los equilibrios de Nash, de modo que cuando cada individuo piensa que el otro escoge tal o cual solución, esta se realizará y las previsiones se confirmarán; $b$ ) la relevancia de la atribución mutua de estados mentales cntre los agentes: «A cree que $B$ cree que. ., Se verá más abajo la importancia de esta circunstancia.

${ }^{15}$ El peculiar sistenta de retribuciones asegura que «se busca la verdadn. El frecucnte wraudes de las ciencias socialcs no tiene que ver con una peor «naturaleza* de sus practicantes, sino con el mal funcionamiento del algoritmo; F. Ovejero, «Kuhn y las ciencias deshonestas", Claves de la razón jrácfica, 71, 1997.

${ }^{16}$ De hecho, bajo ciertas circunstancias, cuando tos sujetos perciben que la tasa de crecimiento real es inferior a la que ascgura cl crecimiento equilibrado e intentan acercarse, las dos tasas se alejan, Para varios ejemplos, cfr. F. Ovejero, La quimera féril, Barcelona, Icaria, 1994, pp. 176-178, notas 17, 18, 19. En tado caso, no debe confundirse la estabilidad con el problema más general de la ubtención de trayectorias históricas. En este caso hay dos dimensiones funcionando: a) direccionalidad o no direccionalidad de proceso, b) contingencia o causalidad entre las secuencias. En la naturaleza se pueden dar los cuatro casos posibles. La estabilidad seria un caso particular de causalidad (mecanismo) y direccionalidad (equilibrio). Para algunas ideas cfr. E. O. Wright, A. Levine, E. Sober, Reconsthucting Marxism, N. York, Verso, 1992, pp. 61-100.

$"$ Ia fórmula paradigmática ha sido la comparación cutre la selección natural y cl mercado como procesos creativos y ciegos. El ejemplo clásico es Hayek, obviamente. De todos modos, la moderna economía evolucionista empieza por criticar la comparación hayekiana, cfr. G. Hodgson, Econonía y ewolución, Madrid, Celeste, 1995, caps. 11 y 12; V. Vanberg, "Spontaneous market order and social rules", Economics and Prilosophy, 2, 1986. Los economistas evolucionistas han buscado alejarse tarto del supuesto de equilibrio como del supuesto de individuos maximizadores. Sin embargo, como hadestacado P. Krugman ( $\alpha$ What economists can learn from evolutionary theoristss, Conferencia en la European Assoctation for Evolutionary Economics, noviembre 1996), Ja propia biologia evolucionista (al menos sus teóricos mấs wadaptacionistas") camina, respecto a aquellos supuestos, en la dirección de la economia nenclásica. Cumo se señala en la siguiente nota, hay más economia de inspiración evolutiva que la que 
Hodgson sistematiza en su ya clásico trabajo. E] desarrollo de la teoria de la complejidad ha convertido tanto la evolución biológica como los procesos económicos en modelos de sistemas măs básicos; cfr. J. Hollan, "Complex Adaptative Systems», Dacdalus, 1992; $\mathrm{S}$. Kauffman, At Home in the Uhiverse. The Search for Laws of Complexity, Londres, Penguin, 1995.

3 Para una completa reconstrucción de la teoria de la mano invisible, la teoria del equilibrio general, y sus limitaciones derivadas de que wel problema de la matentatización (antes que el vigor explicativo) fue la razón bäsica de su creación y desarrollow, eftr. B. Ingrao, G. Israel, The Invisible Hand, Cambridge, Harvard U. P., 1994, p. x. Cfr. asimismo J. Eawtell, M. Milgate y P. Newman (eds.), The Invisible Hand, N. York, Norton, 1987. Vale decir que el interés por los sistumas de emano invisible» ha ido más allá del mercado: P. Krugman, La organización espontanea de La economia, Barcelona, $\Lambda$. Bosch, 1996. El desarrollo de los sistemas dinamicos no lineales y de la teoría de cans ha llevado a un amplio programa de investigacjón que ha abandonado sl clasico matrimonio eon la teoría (bấsicamente estática) del equilibrio general. Cfr. R. Day y P. Chen (eds.), Nonlintar dynamics and evolutionary economics, Oxford, Oxford U, P., 1993. De hecho, entre los pioneros y más refinados cultivadores destacan economistas que entroncan con la tradición clásico marxista-keynesiana: W. Goodwin, Chaotic Economic Dynamics, Oxford: Oxford U. P., 1990.

19 Para los pasos citados y para la formación científico-natural de A. Smitb, en especial su excepcional relación con las fuentes del darwinismo, $\mathrm{cfr}$. F. Ovejero, De la naturaleza a la sociedad, Barcelona, Península, 1985, pp. 116-136.

a) G. Brennan y P. Pettit, *Hands invisible and intangiblew, Symthese, 94, 1993.

a) Tesis que acostumbra a confundir dos *egolsmos" bien Jiferentes: el evolutivo, que ticne que ver con que las consecuchcias de mis acciones aumenten mi eficacia reproductiva, y el psicolögico, que se reficre a mis intenciones y a mis intereses. Que el primero ha de existir en el proceso evolutivo es una simple tautología. Llamar a eso egoismo simplemente es maltratar las palabras. Por otra parte, lo que no resulta autorizado decir es que hay razones evolucionistas en favor de la hipótesis del egoismo psicológico, cfr. $\mathrm{E}$. Sober, From a Biological Point of View, Cambridge, Cambridge U. P., 1994, pp. 8-27. Para atgoritmos que muestran el cartcter evolutivamente estahle de las estrategias cooperativas, M. Nowak, R. May y K. Sigmund, "La aritmética de la ayuda mutuas, Investigación y Ciencia, 227, 1995; T. Besgstrom y O. Stark, "How altruism can prevail in an evolutionary cnvironment», American Economic Review, 2, 82, 1993. En un sentido parecido, $P$. Kitcher ha mostrado cómo resultan eficaces las estrategias de discriminating altrism, que colaboran con aquellos que hasta el momento nunca ban traicionado, "The evolution of Human altruism», Joumal of Philosophy, 90, 1993, Para un panorama, a partir de la anterior distinción entre egoismos, cfr. N. Serurdic, "Recent work on Human Altruism and Evolution», Ehics, 106, 1995; una completa antologia procedente de la cconomia, S. Zamagni (ed.), The Economics of Altruism, Vermont, Edward Elgar, 1995.

22 Op. cit., p. 495

2 La operación habitual ha consistido en buscar una garantía en los genes de los supuestos egoistas de la teoria de la clección racional o de la microeco. nomía. Lo cierto es que la operación ha sido con frecuencia bastante torpe. Así, G. Becker, a la vez que defendía el clásico sirtealismo* de los supuestos, la tesis de que hos supuestos no se calibran por su plausibilidad empirica, buscaba urgentes *fundamentaciones naturalistasa en la sociobiología. Cfr. F. Ovejero, eEl imperio de la economín, Claves de la razón práctica, 58, 1995; J. Elster, More Than Enough. Review of $\mathrm{G}$. Becker, Accountig for Tastes, The University of Chicago Law Review, 62, 2, 1997. En la misma dirccción, en la obtención de una steoría bioeconómicas de la sexualidad on términos de costos-beneficios, ctr. R. Posner, Sex and Reason, Harvard, Harvard U. P., 1992. Para una crítica minuciosa, $M$. Nussbaum, "Only-Grey Matter"? Richard Posner"s Cost-Benclit Analysis of sex», The thiversity of Chicago Law Review, 591, 1992, pp. 1689-1734. De todos modos, conviene advertir que no todas las teorias de la negociación muestran confianza en las explicaciones evolucionistas. Véase, por cjemplo, los escépticos comentarios de D. Gauthier, al sugerente trabajo de A. Gibard, Wist Choices, Apt Feclings (Cambridge: Harvard U. P., 1990), en Morality and Biology?», G. Wolters y J. Lennox (eds.), Concepts, Theories, and Rationality in the Biological Sciences, Pitlsburgh, University of Pittsburgh Press, 1995.

${ }^{4}$ No es casual que se hable de kexplicacionts de nano invisibles precisamente para referinse a explicaciones en las que funciona un mecanismo algoritmico, como la selección natural; por ejemplo, D. Dennet, Darwin's Dangerous Idea, N. York: Simon, Schuster, 1995 , p. 316 . De todos modos, el reconocimiento de la presencia de un proceso algorítmico como el que se da en la selección natural no deberia llevar a conclusiones del tipo wel darwinismo actúa tanto en las modas láser y las biomoléculas como en los hiperciclos y en los reinos animil y vegetals ( $H$. Haken, Secreto de los éxios de la naturaleza, Barcelona, Argos-Vergara, 1984, p. 78). Eso cs como decir que porque se hace uso de la teoría de la optimización, todo es microeconomia. Sencillamente las distintas teorías que pueden utilizar una teoría formal comparten cicrtos isomorfismos y por eso pueden aplicar las mismas herramientas. No por ello se reducen unas a otras ni son casos particulares de la teoría matemática de que se sirven. Se necesita conocer primero si se din las propiedades que permiten hacer uso de la teoría y cllo requiere de la exploración especifica del campo de una teoria. En el presente caso hay que saber que se dan ciertos patrones en condiciones de copiarse, variar ncasionalmente, competir y heredarse. Y para 
saber que eso lo pueden hacer los genes y no gtras entidades, hay que tener una teoria acerca de cómo son, de sus propiedades.

3 A. Hamilton (1788), The Federalist Paper, N. York, Penguin, 1961, p. 437.

t6 Requiere, por de pronto, un alto grado de confianza, entendida como «cierto nivel de probabilidad subjetiva de un individuo que le permite estimar que otros individuos realizarán ciertas acciones, antes de que pueda controlarla (o aun sin que pucda llegar a controlatla) en un marco tal que su propia acción se ve afectada», D. Gambetta, "Can we trust trust?», D. Gambetta (ed.), Trust, Oxford, Blackwell, 1988, p. 217. Para las diversas formas como cl capitalismo mina la confianza como cimiento de la vida social, cfr. A. Seligman, The problem of trisst, Princeton, Prinseton U. P., 1997.

27 Bienes que se consumen sin rivalidad (mi consumo no reduce el tuyo) y sin exclusión (todos gozamos de la misma cantidad).

2s $\mathrm{G}$. Winston, wThree problems with the treatment of time in economics", $G$. Winston y $R$. Teichgraebet (eds.), The boundaries of econamics, Cambridge, Cambridge U. P., 1988.

* Una sintesis actualizada en B. Gofman, «political Economy: Dowsian Perspectives», en R. Goodin y H. D. Klingeman (eds.), A New Handbook of Political Science, Oxford, Oxford U. P., 1995. En Jos útimos años, modelos emparentados con la teoría de la elecciôn racional han buscado aumentar su plausibilidad (con atención, por ejemplo, a los procesos de formación de preferencias) y se han alejado de las explicaciones en términos de mercados, cfr. $\mathrm{K}$. Monroe (ed.), Comtemporay Empirical Political Theon, Berkeley, University of California Press, 1997; D. Mueller (ed.), Perspectives of Public Choice, Cambridge, Cambridge U. P., 1997.

* G. Brennan, \&Selection and the currency of rewardw, R. Goodin (ed.), The Theory of Institutional Design, Cambridge, Cambridge U. P., 1996, pp. $257-258$.

"F. Ovejero, xTres ciudadanos y el bienestar», $\mathrm{La}$ politica, 3, 1997, pp. 98-99.

${ }^{32}$ Aunque ni siquiera. En palabras de uno de los más refinados cultivadores de la teoría del cquilibrio: ¿La economía del mercado y el sentido del orden no son compatibles... Nunca se ha demostrado que sea cierto que la economia de mercado consigue orden, ni siquiera para la economía abstractam, F. Hahn, «Lo que pueden o no hacer los mereadosm, El Trimestre Econónico, 241, LXI(1), 1994.

3 R. Frank, T. Gilovich y D. Regan, *Docs Studying Economics Inhibit Cooperation?, Joumal of Economic Perspectives, 7, 2, 1993.

34 Con más precisión, los equilibrios de Nash (situación en la que los individuos no tienen ningún incentivo para cambiar de estrategia mientras los otros no cambien la suya) no son optimos: en ausencia de cooperación se darấn los equilibrios aư cuando existen resultados mejores. El problema no es que los mer- cados den pie a equilibrios subóptimos, sino que socavan una cooperación que es precisamente la vía para superar diversos problemas de coordinación y bienes públicos. Para los diversos mecanismos, cfr. S. Bowles, *Mandeville's mistake: The Moral autonomy of the self-regulating market reconsidered, Ethics and Economics, University of Siena, Siena, 1991.

* Accrca de si la justificación se vincula con un principio que vale para todos (consensual) o con distintos principios, uno para cada participante (convergentista); acerca de si la justificación tiene base cognitiva o simplemente volicional, o acerca de si la justificaciốn es pragmática, según descos o creencias reales, o trascendental, según el mejor yo ("a reason for her" versus sa reason to hes en la terminología do Williams). Cfr. D'Agostino, Free Public Reason, Oxford, Oxford U. $P_{3}$ 1996. Para una sugestiva revisión de los grados (incompletos) de acuerdo en la deliberación, cfr. C. Sunstein, ancompletely theorized agreements", Harvard Law Review, 108, 1995 , pp. 1733-1772.

${ }^{36}$ B. Manin, «On legitimacy and political deliberation", Political Theon, 15, 1987.

3 Por una parte, hay problemas de compatibilidad. La justificación pública ha de satistacer una serie de requisitos adenás de la fuerza vinculante (robustez, carácter inclusivo, relevancia informativa) que no sienpre apuntan en la misma dirección, D'Agostino, «The Idea and the Ideal of Public Justificationn, Social Theory and Practice, 18, 2, 1992. Por otra parte, hay razones epistémicas derivadas de la distinción entre creencia, entendida como una disposición a sentir una proposición como verdadera, y aceptación, la adopción de una proposición como un principio de actuación, en un contexto determinado, sin atender a si se juzga verdadero o no, J. L. Cohen, A essay on Belief and Aceptance, Oxford, Oxford U. P., 1992, p. 115.

3 No se trata de una teoría empirica de la democracia ni tampoco de una propuesta política. Para ser exacto, es una fundamentación epistémica que puede, eso si, justificar propuestas politicas, cfr. F. Ovejero, «Teorias de la democracia y fundamentaciones de la democracia», Doxa, 19, 1996.

${ }^{39}$ R. Merton, La sociologia de la ciencia, II, Madrid, Alianza, 1977 , pp. 355 y ss. También cabe reconocer el plano de las reglas de competencia, del juego de incentivos de las comunidades cientificas, P. Stephan, aThe Economics of Scicnocn, Joumal of Economic Literutice, XXXIV, 1996, pp. 1199-1235.

40 . Skinner, wMachiavelli on the Maintenance of Libertys, Politics, 18, 1983. Para una exposición sistemática, P. Pettit, Republicanism, Oxford, Clarendon Press, 1997.

"1 F. Ovejero, «Tres ciudadanos...r, art cit

${ }_{42}$ M. Hechter, Principles of Group Solidario, Berkeley, University of California Press, 1987; B. Frey $y$ I. Bohnet, «Cooperation and fairness in experiments: relevance for democracya; $J$. Casas Pardo y $F$. Schnei der (eds.), Current Issues in Public Choice, Edward Elgar, Cheltuham, 1995. 
${ }^{43}$ Cfr. nota anterior.

4 Para el homo oeconomicus esa posibilidad no plantea problemas, resulta acorde con su egoismo entender el escenario social cono lugar de trapicheo.

43 Aunque no sea lo que aquí interesa, conviene advertir que, para muchos problemas de coordinación y cficiencia, las conductas cooperativas o altruistas funcionan mejor que cl mcrado: $\mathrm{S}$. K. Kolm: La bonne économie: La reciprocité général, Paris, PUF, 1984; H. Moulin, Cooperative Microeconomics, Londres, Prentice IIall, 1995, cap. 5.

16 Que no excluye, antes al contrario, la preocupación prioritaria por los propios proyectos, efr. $M$. Slote, From Morality to Virtue, Oxford, Oxford, 1992; y el número dedicado a Self-interest de Social Philosophy and Policy, 14, 1, 1997, especialmente los Irabajos de Wolf, Badhwar, Slote, Bink y Hurka.

47 Sea cn clave aristotélica (M. Galston, *Taking Aristotle Seriously: Republican-oriented Legal Theory and the Moral Foundation of Deliberative Demo. cracy», Califomia Law Review, 82, 1994, pp. 331-399) o roussoniana (J. Spitz, op. cit).

48 Y la propia teoría del mercado. Durante mucho tiempo la teoría cconómica defendís su despreocupación por las motivaciones con argumentos conductistas o de parsimonia metodológica. Sin embargo, esa despreccupación se traduce en importantes insuficiencias analiticas. Sobre el estrecho consecuencialismo de la teoría económica y sobre sus implicaciones, cfr. E. Anderson, Value in Ethics and Economics, Cambridge, Harvard U. $P_{\text {, }}$ 1993. Para un intento de recuperar las motivaciones con instrumental economico, cfr. $J$. Morse, "Who is rational economic man?", Social Philosophy and Policy, 14, 1, 1997.

49 También desde el bienestar, desde su motivación básica: T. Scitovsky, Frustraciones de la riqueza, México, FCE, 1986. Sobre los vinculos psicologicos entre felicidad y preferencias del homo acomicus, cfr. el número dedicado al importante trabajo de Scitowsky, Critical Review, 10, 4, 1996.

${ }^{53} \mathrm{R}$. Tronto, «Beyond Gender Difference: to a Theory of Caren, Sings, 12, 4, 1987; M. Nussbaum, aCompasion: the Basic Social Emotion", Social PhiLosophy and Polity, 13, 1, 1996. Sobre el descuido de las teorias normativas por los aspectos motivacionales, cfr. el ya clásico M. Stocker, "The Schizophrenia of Modern Ethical Theories», Journal of Philosophy, 73, 1976 , pp. 453-456.

st Sobre cstas funciones weconómicas̀ de las emociones, cfr. R. Frank, Passions within Reasons: The strategic role of the emotions, N. York, Norton, 1988. Un repaso de la abundante experimentación que muestra cómo funcionan emociones o principios espontáncos de justicia que violan principios de racionalidad económica, A. Roth. aBargaining Experiments», en J. Kagel y E. Roth (eds.), The Handbook of Experimental Economics, Princeton, Princeton U. P., 1995. Sobre las implicaciones para la microeconomia, que es como decir la teoria del morcado, R. Thaler, Quasi Rational Economics, N. York, Rusell Sage, 1994, pp. 199 y ss,
Sobre las implicaciones para la vida civica del entramado de normas y emociones, C. Sunstein, «Social Norms and Social Roles", Columbia Law Review, 96 , 1996 , pp. 903-968.

$\$ 2$ D. Sperber y D. Wilson, Relevance $\left(2^{\mathrm{a}}\right.$ ed.), Oxford, Backwell, 1995, p. 45. Fúrmula que es un desarrollo de la idea de "conocimiento común (mutuo)" de D. Lewis, Convention, Cambridge, Harvard U. P., 1969. Resulta interesante destacar que una idea parecida (wthe tacit cognitive communalities"), kentre el instinto y la razón es formulada desde la teoría de la elección racional para referirse a los contextos normativos, $\mathrm{U}$. Witt, «Moral norms and rationality within populations: an evolutionary theory", J. Casas Pardo y F, Schneider (eds.), op. cit, p. 251.

${ }^{3}$ F. De Wall, Good Nature. The origins of right and wrong in humans and other animals, Cambridge, Harvard U. P, 1996, pp. 28-29. De Wall muestra sus dudas acerca de las emociones en los animales no humanos, ibidem, p. 108.

\$4 A. Damasio, El error de Descartes, Barcelona, Crítica, 1996. Dos panorámicas del conocimiento psicobiologico sobre emociones: R. Plutchik, The Psychology and the Biology of Emotion, N. York, Harper Colins, 1994; K. Oatley y J. Jenkins, Understanding Enotions, Oxford, Blackwell, 1996.

ss Para interesantes conjeturas acerca del vinculo entre emociones, normas y coordinación, cfr. A. Gibbard, op. cit; R. Solomon, A Passion for Justice. Emotions and the Origin of the Social Contract, Boston, Row$\operatorname{man}, 1995$.

st Que no se elija la capacidad emocional es cosa distinta de elegir las emociones. Las emociones se corrigen como se corrigen las ideas o los errores al inferir. Que tengan base biologica no quiere decir que no se puedan valorar. Sobre tales aspectos: $R$. De Soasa, The rationality of emotion, N. York, Harper Collins, 1994; F. Schocman (ed.), Respensibitity, Character and Emotions, Cambridge, Cambridge U. P., 1987.

57 La explicución (de la psicología evolucionista) radica en que la selección natural prima unos mecanismos cognitivos que favorecen la formación de creencias verdaderas, pero que, a la vez, han de satisfacer otras exigencias (fiabilidad, robustez, rapidez, acceso a la información, economía, etc.), cfr, L. Cosmides y J. Tobby, aBeyond intitution and instintive blindness: Toward an evolutionary rigorous cognitive sciencem, Cognition. 50, 1994; aFrom Evolution to Behavior: Psychology as the Missing Link», J. Dupré (ed.), The Latest on the Best: Essays on Evolution and Dptimality, Cambridge: MIT Press, 1987. Un panorama en H. Barkow, L. Comides y J. Tooby (eds.), The Adapted Mind, Oxford, Oxford U. P., 1992. Para el caso de la visión en términos conputacionales (más tarde incorporados en clave adaptativa por los psicólogos evolucionistas) cfr. D. Mari, La visión, Madrid, Alianza, 1985. Para una valoración critica y mesurada, cfr. E. Stein, Without Good Reason, Oxford, Clarendon Press, 1996, cap. 6. Una discusión de la significación de los supuestos experimentales de tales trabajos (el alcance del condicional) 
para las conclusiones sobre el vínculo entre racionalidad, vida social y evolución, en J. Fetzer, sEvolution, rationality and tcstability, Symthese, 82, 1990.

5* M. McCloskey, «Intuitive Physics», Scientific American, 4, 284, 1983.

54 F. Ovejero, La quimera féril, op. cit. cap. 4.

*os conomistas han utilizado dos recursos para defender esta estrategia ante la evidencia de que no estaba en el horizonte intencional de los individuos hacer o desencadenar aquello que se quería explicar. El primero, metodológico, con argumentos pragmáticos, justifica la «irrealidad de los supuestos" de comportamiento en nombre de su vigor predictivo. El segundo, teórico, măs reciente, en torpe matrimonio on la socinbiología, convertía a los individuos en xinconscientesw envases de los genuinos actores maximizadores, los genes. Como se apuntó en la nota 23 , las dos estrategias no son del todo compatibles, pues si la segunda busca dotar de plausibilidad naturalista a los supuestos, la primera proclama el derecho a descuidar ese soporte.

* Para ser justos, su hábitat originario fuc la telco. logia natural, el designio divino de los organismos al gue se enfrenta la teoría de la selección natural. Los textos clásicos del debate en T. Cosslett (ed.), Science and Religion in the Nineteenth Centruy, Cambridge, Cambridge U. P., 1984. Debate que se modifica después de Darwin. Para el debate contemporáneo entre adaptacionistas y darwinistas moderados, cfr. J. Dupré (ed.), The Latest on the Best, op cit.; C. Allen, Bekoff y G. Lauder (eds,), Nature's Purposes: aralyses of function and design in biology, Cambridge, The MIT Press, 1998. Una formulación sencilla de la discusión desde una perspectiva adaptacionista por un biólogo evolucionista de primera línea: cfr. G. Willams, Plan and Purpose in Nature, Londres, Phoenix, 1996.

$5 z$ Cfr. una reconstrucción dinámica del contrato sucial, incorporando compromisos, convenciones e kinstintos*, en el breve y espléndido ensayo de B. Skymms, Evolution of the Social Contrat, Cambridge, Cambridge U. P., 1996.

63 En un contexto cooperativo, obviamente, la mejor estrategia sería aquella que «aparece» y «desaparece», que sugiere colaboración, pero quc, cuando ticne la confianza, traiciona. Pero, precisamente, la selección natural no permite esa posibilidad, las disposiciones no se pueden elegir, aun si eso se realiza de un modo sofisticado, a través de la capacidad para detectar al free rider. 1996.

M. Ridley, The Origins of virue, N. York, Viking,

as Esa comparación en S. Pinker y P. Bloom, «Natural Language and Natural Selection*, Behavior and Brain Scicnces, 13, 1990, pp. 707-784. Asimismo, S. Pinker, The Language Insinct, Londres, Penguin, 1995, p. 350 .

* Si la inducción fuera segura, no seria inducción, sino deduccion, Es falibie, pero lambien dicaz. En ese sentido sigue resultando pertinente la areinterpretación del a prion kantiano por Lorenz y sus discí- pulos, ch, F. Wuketits (ed.), Cuncepis und appraches in evolutionary epistemology, Dordrecht, Reidel, 1984; R. Rield, Biologia del conocimiento, Barcelona, Labor, 1983. Más interés (mayor base cognitiva) tiene la reciente u(di)solución biológica del problema de la inducción, fundamentada en la idea de que nuestros conceptos están innatamente estructurados de tal modo que presumen la existencia de clases naturales. Lo que ro quiere decir que la epistemologia pierda su carácter normativo: «La evolución no dcbe invocarse como cuidencia de que nuestra psicologia se ajusta bien a la estructura causal del mundo. Ese ajuste debe establecerse independientemente. La evolución sólo cabe invocarla despuếs de haber establecido ese ajusten, H. Kornblith, Inductive Inference and its Natural Grownd, Cambridge, MIT Press, 1993, p. 3. Para un repaso de los diversos aspectos de conocimientos aimplíitoss sedimentados evolutivamente: A. Reber, Intplicit Leaming and Tacit Knowledge, Oxford, Oxford U. P., 1993.

67 Como se senala en una de las exposiciones más sistemáticas de la psicología cvolucionista, hay genes de disfunciones (distrofia muscular, dislexia, Alzheimer, etc.), pero no ade la civilidad, lenguaje, memoria (..) de organismos adaptativos complejosm, S. Pinker, How the Mind Works, Alen Lane, N. York, 1997, pp. 34-35. Cabe conjeturar que lo que en tales casos se localiza es un gen que es condición necesaria para cierta función. Es conocido que las únicas condicioncs suficientes son de sucesos negativos: es suficiente para que la TV no funcione que el cable esté cortado, por ejemplo. Para una visión más uoptimistas de la loca. lización de genes, fr. J. M. Snith y E. Szatmáry, «Language and lifes, M. Murphy y L. O'Neill (eds.), What is Life? The Nex Fify Years. Speculations on the Future of Biology, Cambridge, Cambridge U. P., 1995, p. 76.

La cooperación y el altruismo tienen más de un itinerario. En el trabajo existente más completo sobre cooperación animal, L. Dugatkin sistematiza cerca de un centenar de modelos distintos, Cooperation annongs animals, Oxford, Oxford U. P., 1997, pp. 25-2y.

69 Desde esta perspectiva, la «mente» no aparecería como una inteligencia general útil para todo, sino como una combinación de diversos dispositivos cspccializa. dos en parte programados genéticamente, especiali zados tanto respecto al dominio cognitivo del gue se ocupan como por el tipo de tratamiento de la información. Para una presentación informal de la cvidencia experimental, cfr. M. Gazzaniga, El cerebro social, Alianaa, Madrid, 1995. Una visión más matizada: A Karmiloff-Smith, "Precis of: Beyond Modularity", Behavior and Brain Sciences (en curso de publicación)

74 H. Plotkin, Evolution in Mind, Londres, Alen Lane, 1997 , p. 139. Para una breve y sugestiva exposición del vínculo evolutivo entre vida social y los humanos como «psicólogos naturales», cfr. N. Humprey, $L a$ mirnda interior, Alianza, Madrid, 1993. La atribucion de estados mentales es común a los primates con intensa vida social, cfr. D. Cheney y R. Seyfarth, How monkeys see the world, Chicago, University of Chicago Press, 
1990; C. Alleny M. Bekoff, Species of Mind, Cambridge, The MIT Press, 1997, cap. 6. Para una visión crítica, C. Heyes, "Theory of Mind in Nonhuman primates", Behavior and Brain Sciences (en curso de publicación).

"D. Sperber y D. Wilson, op. cit, pp. 65-72.

7 L. Cosmides, "The Logic of social exchange: has natural selection shaped how humans reason?s, $\operatorname{Cog}$ * nition, 31, 1989.

7 Por esta via se captura con buen fundamento un argumento filosófico tradicional según el cual reconocer a otro como racional supone un principio de respeto y preocupación, T. Nagel, The Possibility of Aluwism, Princeton, Princeton U. P., 1970. Otro tanto se podría decir respecto a la intuición (y la torpeza) utilitarista que toma el sufrimiento como criterio de pertenencia a la comunidad de valoración, lo que lo lleva a incluir sin matices a los animales no bumanos. Para una teoría normativa atenta a los resultados cognitivos, la capacidad de sufrimiento no es independiente de la existencia de unos sistemas articulados de deseos, expectativas, de unos estados mentales complejos y con capacidad discriminatoria, que no se dan por igual en todas las especies. Sencillamente, no todo sufrimientu es igual. Cfr. D. Dennet, «Animal Conscioussnes: What Matters and Why», Social Research: In the Company of Animals, New York City, 1995.

${ }^{4}$ L. Cosmides y J. Tooby, kBeyond intuition...", att. cit., p. 64.

7. J. Tobby y L Cosmides, wriendship and the Banker's Paradox: Other Pathways to the Evolution of Adaptations for Altruism», W. Runciman, J. Maynard Smith y R. Dunbar (cds.), Evolution of Social Behavior
Patterns in Primates and Man, Oxford, Oxford U. P., $1996, \mathrm{pp}, 129-130$.

* D. Sperbet, *Modularité mentale et diversité culturellew, Le contagion des idées, París, Editions Odile Jacob, 1996, p. 166. Asimismo, S. Atran, *Folk Biology and the antropology of Science: Cognitive Universals and Cullural Particulars;, Behavior and Brain Sciences (en cursa de publicación).

"Que se ha dado en llamar, por oposición al «Modelo Estándar de las Ciencias Socialesn, *Modelo Causal Integrado». Para una presentacion programática, L. Cosmides y J. Tooby, Evolutionary Psychology: A Primer, s.f.

38 "Los conservadores (que atacan el estado del bienestar) quizá no sean unos peligrosos románticosn, $\mathrm{M}$. Ridley, op. cit., p. 262. No es la única inferencia urgente de este urgente ensayo de ciencia popular. Lo cierto es que, con todo lo que hay de sugestivo en el programa de la psicología evolucionista, no resultan intrecuentes estas maneras (es el caso, por ejemplo, de R. Wright, The moral animal, Londres, Abacus, 1996, o de bastantes páginas de D. Buss, La eyolucion del deseo, Madrid, Alianza, 1996.

${ }^{79}$ S. Pinker, How The Mind Works, op. cit, p. 42. y A.S. Holbacn, en Hirschman, pp. 34-47.

* Sistema de la Naturaleza (1769), Madrid, Editora Nacional, 1982 , p. 332.

* A. Hirschman, Las pasiones y los intereses, México, FCE, 1978.

${ }^{2}$ Adam Smith, The Theory of Moral Sentinents (1759, 1790), Oxford, Clarendon Press, 1991, pp. 321322. 